\title{
The role of biomarkers in osteoarthritis and osteoporosis for early diagnosis and monitoring prognosis
}

\author{
Biyobelirteçlerin osteoartrit ve osteoporozda erken tanı ve prognozun izlenmesindeki rolü
}

\author{
O. Şahap Atik, MD'1D, Erdem Aras Sezgin, MD²D, H. Emre Tepedelenlioğlu, MD² \\ ${ }^{1}$ Professor of Orthopedic Surgery, Turkish Joint Diseases Foundation, Ankara, Turkey \\ ${ }^{2}$ Department of Orthopedics and Traumatology, Gazi University Medical Faculty, Ankara, Turkey
}

Osteoarthritis and osteoporosis are two diseases related to the skeletal system that have high incidence rates. ${ }^{[1]}$ The incidence of osteoporosis and osteoarthritis in society is increasing depending on many factors such as increased ratio of the elderly population with prolonged life expectancy, sedentary lifestyle, and malnutrition. ${ }^{[2]}$

The heterogeneity of the human population, lack of complete understanding of the osteoarthritis disease process, and the slow progressive nature of the disease characterized by prolonged periods of nonsymptomatic, degenerative changes led to development of diagnostic and prognostic biomarkers. ${ }^{[3]}$

There are a number of promising candidates for biomarkers such as urinary C-terminal telopeptide of type II collagen and serum cartilage oligomeric matrix protein, while none is sufficiently discriminating for diagnosis or prediction of prognosis in patients or for use as a surrogate outcome in clinical trials. ${ }^{[4]}$ However, the combination of specific markers seems to improve the prediction of disease progression at the individual level. ${ }^{[5]}$

Micro-ribonucleic acids could serve as useful clinical biomarkers in the diagnosis of certain diseases such as intervertebral disc degeneration. ${ }^{[6]}$

Transglutaminase 2 represented a suitable biomarker of osteoarthritic chondrocyte activation, whereas osteocalcin, osteopontin and sclerostin characterized osteoporotic osteocyte/osteoblast changes. ${ }^{[7]}$

The rates of bone production and destruction can be evaluated by assaying bone matrix components released in the bloodstream and excreted in the urine. These are biomarkers of formation: bone-specific alkaline phosphatase, osteocalcin and biomarkers of resorption: N-terminal and C-terminal crosslinking telopeptide of type I collagen. In case both events are coupled and change in the same direction such as osteoporosis, biomarkers will reflect the overall rate of bone turnover. ${ }^{[8]}$

\section{Declaration of conflicting interests}

The authors declared no conflicts of interest with respect to the authorship and/or publication of this article.

\section{Funding}

The authors received no financial support for the research and/or authorship of this article.

\section{REFERENCES}

1. Tokgöz MA, Atik OŞ, Esendağlı G, Öğüt B, Bozkurt HH. Is it possible that the pathogenesis of osteoarthritis could start with subchondral trabecular bone loss like osteoporosis? Eklem Hastalik Cerrahisi 2018;29:152-8.

2. Bozkurt HH, Atik OŞ, Tokgöz MA. Can distal radius or vertebra fractures due to low-energy trauma be a harbinger of a hip fracture? Eklem Hastalik Cerrahisi 2018;29:100-3. 
3. Patra D, Sandell LJ. Evolving biomarkers in osteoarthritis. J Knee Surg 2011;24:241-9.

4. Bruyère $\mathrm{O}$, Cooper $\mathrm{C}$, Arden $\mathrm{N}$, Branco J, Brandi $\mathrm{ML}$, Herrero-Beaumont $G$, et al. Can we identify patients with high risk of osteoarthritis progression who will respond to treatment? A focus on epidemiology and phenotype of osteoarthritis. Drugs Aging 2015;32:179-87.

5. Rousseau JCh, Garnero P. Biological markers in osteoarthritis. Bone 2012;51:265-77.

6. Zhou X, Chen L, Grad S, Alini M, Pan H, Yang D, et al. The roles and perspectives of microRNAs as biomarkers for intervertebral disc degeneration. J Tissue Eng Regen Med 2017;11:3481-3487.

7. Tarquini C, Mattera R, Mastrangeli F, Agostinelli S, Ferlosio A, Bei $\mathrm{R}$, et al. Comparison of tissue transglutaminase 2 and bone biological markers osteocalcin, osteopontin and sclerostin expression in human osteoporosis and osteoarthritis. Amino Acids 2017;49:683-693.

8. Garnero P, Delmas PD. Contribution of bone mineral density and bone turnover markers to the estimation of risk of osteoporotic fracture in postmenopausal women. J Musculoskelet Neuronal Interact 2004;4:50-63. 